\title{
A ESCOLA, O PROFESSOR E O ALUNO: CONSIDERAÇÕES SOBRE O PAPEL DA EDUCAÇÃO NA SOCIEDADE CAPITALISTA
}

\section{THE SCHOOL, THE TEACHER AND THE STUDENT: CONSIDERATIONS ON THE ROLE OF EDUCATION IN CAPITALIST SOCIETY}

\author{
Carla Cristina Castro Araujoํ, Reginaldo Peixoto², Maria Silvia Rosa Santana ${ }^{3}$
}

Submetido em: 24/04/2020

Aprovado em: 09/02/2021

\section{RESUMO}

A sociedade capitalista infere a pensar no tipo de educação que a escola sob os princípios desse sistema impõe para a sociedade de classes. A partir de uma revisão bibliográfica sobre conceitos do Materialismo Histórico-Dialético e da Pedagogia Histórico-Critica, buscou-se a análise da realidade da escola atual com vistas a contribuir com algumas constatações acerca da sua função e no papel do professor, para a sua possível transformação. O objetivo é o de descrever a função social da educação na escola capitalista, com breves considerações sobre a sua intencionalidade na história reproduzida no trabalho docente. O texto apresenta conceitos que, em sua totalidade, estabelecem os princípios que orientam essa concepção de educação e de ensino, baseados na formação do pensamento teórico, a saber: sociedade capitalista, educação, escola, professor, pensamento teórico, entre outros conceitos. Fundamenta o campo conceitual do professor e da escola a partir da sistematização e análise desses conceitos e das relações a eles intrínsecas. Conclui-se que foi realizado um "exercício" sobre a necessidade de refletir e conscientizar sobre as possibilidades educativas do aluno por meio de uma visão crítica da sociedade atual, assim como, constatar as condições limitantes que a escola propõe aos seus educandos, dificultando sua transformação e humanização e, de certa forma, preparando para o ajustamento econômico do capital, por meio da força de trabalho.

PALAVRAS-CHAVE: Sociedade capitalista. Escola. Pedagogia Histórico-Crítica. Professor.

\section{ABSTRACT}

Capitalist society implies thinking about the type of education that the school under the principles of this system imposes on class society. From a bibliographic review on concepts of Historical-Dialectic Materialism and Historical-Critical Pedagogy, an analysis of the reality of the current school was sought in order to contribute with some findings about its function and the teacher's role, for its possible transformation. The objective is to describe the social function of education in the capitalist school, with brief considerations about its intentionality in the history reproduced in the teaching work. The text presents concepts that, in their entirety, establish the principles that guide this conception of education and teaching, based on the formation of theoretical thinking, namely: capitalist society, education, school, teacher, theoretical thinking, among other concepts. It bases the conceptual field of the teacher and the school from the systematization and analysis of these concepts and the intrinsic relations to them. It is concluded that an "exercise" was carried out on the need to reflect and raise awareness about the educational possibilities of the student through a critical view of the current society, as well as, to verify the limiting conditions that the school proposes to its students, hindering their transformation and humanization and, in a way, preparing for the economic adjustment of capital, through the labor force.

\section{KEYWORDS: Capitalist society. School. Historical-Critical Pedagogy. Teacher.}

\footnotetext{
${ }^{1}$ Aluna do Programa de Pós-Graduação - Mestrado em Educação da Universidade Estadual de Mato grosso do Sul. e-mail: psicarlacastro@hotmail.com

2 Professor adjunto do curso de Pedagogia e Mestrado em Educação na Universidade Estadual de Mato grosso do Sul. e-mail: regi.peixoto77@gmail.com

${ }^{3}$ Professora adjunta do curso de Pedagogia e Mestrado em Eduçação na Universidade Estadual de Mato grosso do Sul. e-mail: mariaros_664@hotmail.com
} 


\section{INTRODUÇÃO}

Atualmente no Brasil, em virtude da instabilidade político, social e econômica dos últimos anos, nota-se uma preocupação por parte de algumas ideologias políticas em relação a uma vertente teórica formativa ofertada na área de educação, o que tem redundado em menos investimentos pelo Estado na escola pública, causando um efeito cascata na qualidade do ensino e da aprendizagem. O que acarreta no indivíduo dificuldades quanto ao desenvolvimento pleno de suas potencialidades e torna difícil a própria compreensão da educação. Questiona-se a intencionalidade dos detentores do poder na sociedade de classes sobre as políticas educacionais e os reflexos sobre os aspectos da história da educação no Brasil, quando se considera o entrelaçamento desta forma de sociedade e a escola como parte constituinte, que busca direcionar a forma como se coloca atualmente em sua totalidade.

Uma vez que a realidade escolar tem refletido o fracasso da instituição enquanto instrumento de acesso ao conhecimento pleno e universal, nota-se a necessidade de conhecer, analisar e refletir acerca dessa realidade a fim de atuar conscientemente sobre o que está posto. A luta por uma escola transformadora é variável nas necessidades da sociedade de classes e, por isso, o indivíduo, no mínimo, deve ter consciência de sua condição social, para assim compreender sua capacidade produtiva em busca de superar suas limitações sociais, especialmente as educacionais.

A partir dessas considerações iniciais, questiona-se: o que se entende pela função da educação na escola capitalista em seu processo histórico? Como o papel do professor se constituiu mediante essa determinação social? Como o professor pode atuar nas práticas educativas numa sociedade capitalista? Em que medida é possível lutar por uma escola humanizadora e transformadora?

Para compreender os desafios que estes questionamentos promovem, parte-se da premissa de que a educação se dá por uma construção histórica a partir da relação dialética entre os indivíduos e com a sociedade e o mundo material. Este artigo tem como objetivo descrever a função social da educação na escola capitalista, com breves considerações sobre a sua intencionalidade na história, reproduzida no trabalho docente. Demonstrar que a educação, ao estar entrelaçada à sociedade de classes, é distorcida da realidade escolar transformadora, com o intuito de limitar o acesso pelo indivíduo ao conhecimento sistematizado historicamente, para atender aos interesses das classes mais favorecidas economicamente, especialmente o não desenvolvimento pelo indivíduo da consciência de sua realidade, o que possibilitaria transformá-la.

Desta maneira, refletir possibilidades junto à atuação do professor na efetivação de uma escola transformadora e humanizada leva ao desafio de superar as contradições de um padrão de ensino estático e limitante. Deve-se considerar as condições objetivas do determinado contexto social, tornando-se de fato a escola um espaço formal e a educação um meio de acesso com qualidade ao conhecimento científico, universal. Para isso, apresenta-se como norte deste texto uma revisão bibliográfica, com destaque para alguns conceitos do Materialismo Histórico Dialético e da Pedagogia Histórico-Crítica, ampliando a análise da realidade escolar e, assim, contribuir com algumas considerações, para possíveis reflexões.

\section{A EDUCAÇÃO NA SOCIEDADE DE CLASSES: FUNÇÃO E INTENÇÃO DA DIVISÃO ECONÔMICA SOCIAL E POLÍTICA NA ESCOLA}

Para compreender a função da educação escolar na atualidade, reporta-se a Freres, Rabelo e Mendes Segundo (2008, p. 08) por afirmarem que: "[...] a crise que estamos vivendo atualmente é uma crise que tem como base o trabalho explorado, que mata os homens em vida. Essa crise rebate na educação e em todos os complexos sociais expõe as contradições do sistema do capital", ou seja, a escola, dentre outras instituições, evidencia uma exploração nas formas de trabalho, pois os sujeitos que participam dela tendem a promover os discursos e as ações que estão impostas no sistema capitalista, seja por meio das relações de poder, do currículo ou da força de trabalho dos professores.

Nesse sistema, que por hora também arrebata a escola, é um erro acreditar que a educação irá resolver “[...] 
os problemas da humanidade que foram gerados pelo tipo de organização social que aprofundou o contraste entre pobreza e riqueza. A educação nunca vai resolvê-los, pois enquanto o capital continuar como sistema vigente, a humanidade agonizará". (FRERES; RABELO; MENDES SEGUNDO, 2008, p. 08).

A crise da educação se expressa na contradição da vida, em que o sujeito, limitado de seu sentido humanizador, necessita repensar seus valores e atitudes para retomar a escola enquanto possibilidade de mudança de sua condição de vida e de suas relações. Por isso, Saviani (2002) corrobora na discussão sobre educação e humanização, ao destacar que a origem da educação coincide com a origem do homem, ou seja, ao entender a realidade humana estaremos em busca de compreender a educação. Dessa forma, apreender a realidade da escola na sociedade capitalista em sua historicidade a partir de determinado momento, possibilitará refletir sobre os aspectos a serem superados na educação.

A educação escolar que se apresenta na atualidade como a solução dos problemas humanos, parece ser uma afirmativa falsa, conforme explicita Silva (2018, p. 447):

Assim, parece-nos que a solução (educação escolar) defendida por governos, empresários, educadores e leigos, para o problema das péssimas condições de vida e das relações entre seres humanos, ou como caminho para emancipação, é falsa, já que não considera que a forma de organização da produção se movimenta por meio de mecanismos de sua lógica própria (a exploração do trabalho; a produção de mais-valia, valor, capital e sua expansão) como produtora também da realidade a sua volta.

A escola, instituição social que representa a sociedade na qual se insere, de acordo com o autor do excerto, ainda que seja pautada nos discursos políticos, econômico e social como a salvação da humanidade, pouco tem feito, pois seus princípios são acometidos pelas relações sociais, de trabalho e de exploração humana que se vislumbram no sistema capitalista, por isso, ela pode pouco fazer.

Ponce (1995) contextualiza historicamente a constituição da escola, expõe a transição das comunidades feudal para a capitalista, cuja função é incentivar a competição, e respondendo aos interesses hierárquicos da burguesia, delimitar para quem e qual conhecimento seria acessível nela. Neste sentido, há uma estreita relação entre sociedade e escola, e, portanto, com o mundo do trabalho e a luta de classes. A intenção da burguesia é determinar os papéis sociais, aos quais os indivíduos devem se subordinar e, desta maneira, educar o pobre para aceitar a sua condição, tendo acesso a um conhecimento específico para exercer determinadas tarefas, ou seja, aquelas que convêm para os detentores do poder, com a finalidade de manter o controle social.

Ao discutir esse controle social apresentado por Ponce quando se refere à escola, Nogueira e Nogueira (2002) observam que em "Os escritos de educação", de Bourdieu (1998), o autor deixa evidente que a manutenção do poder nas classes sociais se dá, também, na manutenção da escola que cumpre essa hierarquização. Por isso ela tende a ser de boa qualidade ou não, de acordo com o público que atende.

Assim, o papel da escola numa perspectiva sociológica pode ser enviesado a partir das relações de poder que perpetuam outras instituições sociais, conforme admitem Nogueira e Nogueira (2002, p. 21):

A educação escolar, no caso das crianças oriundas de meios culturalmente favorecidos, seria uma espécie de continuação da educação familiar, enquanto para as outras crianças significaria algo estranho, distante ou mesmo ameaçador. A posse de capital cultural favoreceria o êxito escolar, em segundo lugar, porque propiciaria um melhor desempenho nos processos formais e informais de avaliação. Bourdieu observa que a avaliação escolar vai muito além de uma simples verificação de aprendizagem, incluindo um verdadeiro julgamento cultural e até mesmo moral dos alunos.

De acordo com o excerto, os alunos de classes mais privilegiadas já trazem aspectos da sua cultura para os processos de escolarização, o que acaba determinando uma série de questões, inclusive o modelo de ensino e as avaliações a que são submetidos. A avaliação escolar, nesse sentido, além de um recurso de verificação de 
aprendizagem do conhecimento escolar, pode ser observada como um julgamento do capital cultural e dos modos de vida que separam diferentes crianças pertencentes a diferentes classes sociais.

Para Kosik (1976), o indivíduo não é apenas um ser neutro que pensa sobre a realidade, mas que a partir de sua história age sobre ela e é transformado por ela enquanto natureza e nas relações com outros indivíduos. Por isso, essa realidade não se apresenta aos indivíduos de forma estática, cujo papel destes é apenas "conhecer", como algo dicotômico, separado em sí. Assim, é nesta direção que a divisão de classes se estende para o interior da escola, inicialmente com a educação representada na reprodução dos interesses da classe dominante.

Falseiam a ideia da existência de uma neutralidade da escola, pois assim engessam o conhecimento de acordo com suas intencionalidades, dicotomizando o pensar e o fazer, distorcendo a realidade e, por conseguinte, mantendo a dominação de classe, ou seja, a superioridade no conhecimento sobre aqueles que detêm menos poder econômico. A ignorância do homem dominado o leva à marginalização e a escola se reformula enquanto "proposta" de tirá-lo dessa condição. Esta, com o tempo, se torna um direito e é universalizada, mas ao mesmo tempo, mascara o acesso ao conhecimento, permanecendo a rejeição e exclusão social, mantendo condições subordinadas aos interesses burgueses.

Para Nogueira e Nogueira (2002), a escola tende a reforçar o capital cultural do sujeito, por isso ela reflete a institucionalização do saber, não somente científico e sistematizado, mas do aprendido nos meios que cada sujeito vive, conforme afirma o excerto:

Cobra-se que os alunos tenham um estilo elegante de falar, de escrever e até mesmo de se comportar; que sejam intelectualmente curiosos, interessados e disciplinados; que saibam cumprir adequadamente as regras da 'boa educação'. Essas exigências só podem ser plenamente atendidas por quem foi previamente (na família) socializado nesses mesmos valores. (NOGUEIRA; NOGUEIRA, 2002, p. 21).

De acordo com o excerto, os processos escolares não dialogam com as vivências dos sujeitos escolares, especialmente os da escola pública. O que se espera do aluno das classes populares, por exemplo, se espera de todos os demais e, no entanto, as exigências feitas pela escola só podem ser respondidas na medida que elas são presentes no dia a dia desses sujeitos, ou seja, modos corretos de falar e comportamentos adequados, por exemplo, só são possíveis quando estão presentes na cultura familiar de cada um. Isso demonstra que o que a escola espera do educando nem sempre é o que ele tende a, ou pode, oferecer.

Para Freres, Rabelo e Mendes Segundo (2008) não há o interesse por uma educação em sua totalidade que se baseie na transmissão de conhecimentos historicamente acumulados pela humanidade, pois o capital é o ponto focal, e a educação cumprirá seu papel de manter os seus interesses, para ter trabalhadores manipulados, presos, junto ao sistema. Assim, a formação do trabalhador deve "[...] possibilitar uma postura crítica e criativa frente ao mundo. Em outras palavras, os indivíduos devem ser formados para aprenderem a criar uma forma de continuar sobrevivendo num mundo que os joga na miséria”. (FRERES; RABELO; MENDES SEGUNDO, 2008, p. 07).

Os problemas a serem enfrentados na escola se transformam de pedagógicos para sociais, tornando o indivíduo responsável pela sua condição escolar. É importante pontuar que para a sociedade capitalista, a universalização e a qualidade do ensino e da aprendizagem na escola não é um problema, desde que mantenha atendendo seus interesses daquele determinado momento histórico. De acordo com Freres, Rabelo e Mendes Segundo (2008, p. 08): "[...] a educação, desse modo, vem se constituindo num importante mecanismo ideológico, responsabilizando cada indivíduo pela sua vida e pela vida da comunidade, que deve desenvolver competências para lutar, sobreviver e ocupar seu espaço nessa sociedade eminentemente concorrencial". Atingir níveis melhores de vida, requer um esforço pessoal, pois de acordo com o protagonismo proposto pelos currículos escolares como a BNCC - Base Nacional Comum Curricular (BRASIL, 2017), a emancipação do sujeito social deve decorrer da sua participação e emancipação.

Nesse sentido, o processo educativo na escola se torna mais objetivo e operacional, com a finalidade de organizar as intencionalidades burguesas e minimizar contrariedades da comunidade à sua proposta. Para Sa- 
viani (1997, p. 24), determina-se "[...] o parcelamento do trabalho pedagógico com a especialização de funções, postulando-se a introdução no sistema de ensino de técnicos das mais diferentes matizes", ou seja, um ensino que cumpre os anseios do sistema capitalista em educar para cumprir funções meramente submissas em atendimento ao mercado de trabalho. Essa emancipação não se vislumbra como independência, mas sim, de certa forma, como uma alienação.

Assim, em cumprimento às determinações do sistema capitalista, é importante manter "[...] a padronização do sistema de ensino a partir de esquemas de planejamento previamente formulados aos quais devem se ajustar as diferentes modalidades de disciplinas e práticas pedagógicas". (SAVIANI, 1997, p. 24). A escola que se prende na armadilha desse sistema distorce e desvaloriza sua função transformadora, para a manutenção do status quo nas relações de poder sobre as classes sociais menos favorecidas. É importante considerar que a formação do professor é permeada pela sociedade que insere a educação sob sua concepção, e por isso atende as exigências do sistema capitalista no trabalho pedagógico. Sua atuação é limitada enquanto ser criativo, ao ser levado pelo tecnicismo e para o desinteresse sociopolítico, quando seu papel é desvinculado da realidade que se insere.

Dessa forma o professor, enquanto sujeito participante e essencial nas relações escolares, é superficial e/ou neutro na função de envolver a educação como instrumento de luta, no desenvolvimento de uma consciência crítica sobre o pensamento comum, com vistas à transformação da realidade determinada pela sociedade capitalista. Sua própria condição é de reprodução, pois assim também se apropriou dos conhecimentos por ter nascido nessa sociedade, e que acaba transmitindo essa ideologia no processo educativo, utilizando práticas de exclusão, percebendo-as como naturais.

Os processos sociais passam a ser vistos de forma naturalizada; a escola é tratada como neutra e democrática, o ensino segmentado em interesses e mantendo uma função segregadora e excludente. Para Facci (2004, p. 10) o objetivo da escola "[...] enquanto uma instituição que possibilita ao indivíduo se apropriar do conhecimento científico produzido pela humanidade, coletiva e historicamente, e, desta forma, conscientizar-se dos limites individuais impostos pelas construções sociais, parece não ser considerado". A escola mantém, e as vezes acirra, a divisão social, e os indivíduos são aprisionados em sua capacidade produtiva e, por consequência, não se humanizam.

Para Mészáros (2008, p. 03),

[...] a educação tem sido chamada, em última análise, a cumprir o papel basilar, não de construir o homem livre e pleno, mas de ajustar os indivíduos aos ditames do trabalho explorado, que é o motor fundamental da dinâmica do capital. O projeto educacional voltado para a reprodução da ordem vem se efetivando, de um modo geral, através da negação do conhecimento que revela as determinações do real em suas múltiplas dimensões, acoplada à manipulação ideológica das consciências, com vistas à naturalização da exploração e de seus desdobramentos no plano da desumanização crescente do próprio homem.

De acordo com o excerto, a educação que deveria ser um processo emancipatório, tem sido um objeto do sistema capitalista, o qual insiste em manter o sujeito preso à sua dinâmica, ou seja, ajusta os indivíduos das classes trabalhadoras para desenvolver os projetos que o sistema impõe, os quais são oriundos da exploração do trabalho e do trabalhador.

\section{A FUNÇÃO DA ESCOLA E O PAPEL DO PROFESSOR ENQUANTO AGENTE DE TRANSFORMAÇÃO}

No contexto de educação como um sistema alienado ao capitalismo, o papel do professor é repensar a sociedade para repensar a educação e, a partir disso, refletir sobre as necessidades e potencialidades, problematizar possibilidades dentro dos limites impostos pela sociedade capitalista e transformar sua prática pedagógica em cada contexto que atua. Dessa maneira se afastará da reprodução, ao utilizar a educação para questionar a realidade circundante e assim, promover mudanças na sociedade.

Por tudo isso, deve, primeiramente, desmistificar crenças e ideias padronizadas a respeito da educação e 
do bom professor e, dessa forma, buscar fundamentar o seu trabalho em teorias, justamente para questioná-las em um processo contínuo de vivências e transformação das práticas profissionais. Por isso, a educação não é neutra e nem estática. Para Puentes (2013, p. 23):

[...] o trabalho do professor pressupõe a identificação das necessidades preliminares dos estudantes e a criação das necessidades comuns ao coletivo de estudantes, de modo que os motivos sejam educados, fazendo coincidir o que move as ações individuais e coletivas no contexto educativo e o objeto a que elas se dirigem (o ensino-aprendizagem-desenvolvimento); implica, ainda, a criação e organização das condições objetivas e subjetivas para a elaboração e o desenvolvimento de atividades de ensino e atividades de aprendizagem, enquanto unidades formativas e formadoras.

O papel político de questionar os limites impostos pela estrutura social é justamente problematizar em conjunto, a fim de buscar alternativas para a superação das dificuldades da realidade escolar e social. Nesse sentido, o professor deve ser ativo, não apoiando apenas nos conteúdos predeterminados, mas entrelaçando-os com a realidade social, sem imposição de opiniões próprias, mas aberto ao diálogo, visando à transformação da sociedade em menos desigual, justa e humana. Para isso, precisa acreditar na educação e conhecer as suas determinações sociais, econômicas e culturais, assim como as de seus alunos, para reconhecer sua prática pedagógica.

Para Duarte (2019, p. 9): "[...] o indivíduo vê-se limitado pela alienação à condição de 'ser humano meramente particular' que, explicado de maneira talvez um tanto simplificadora, pode ser entendido como o indivíduo cuja vida se limita à adaptação ao status quo". A emancipação do sujeito escolar poderia ocorrer a partir da sua criticidade, quando, mesmo que cumprindo as imposições postas pela escola e pela sociedade, reconhece o seu papel diante das armadilhas que o sistema capitalista lhe impõe, não devendo seguir a ordem da naturalização das relações sociais, podendo transformar a sua existência.

Ampliando a discussão, quando se trata de sociedade capitalista, essa adaptação

[...] mostra-se com características distintas para os indivíduos da classe dominante e para os da classe dominada. O que para os primeiros se apresenta como bem-aventurança ou como uma 'justa recompensa' por seus supostos talentos e esforços, para os segundos apresenta-se como uma permanente luta contra as adversidades que renitentemente colocam obstáculos à busca por um lugar ao sol. (DUARTE, 2019, p. 9-10).

É principalmente na escola e com a atuação do professor politizado que se abre possibilidades da transformação social, em especial, das injustiças, como aponta Duarte (2019). É pela instituição estar vinculada ao Estado, que as diferenças aparecem em seu interior, surgindo a necessidade de mudança das condições impostas, embora tenda a conservar os aspectos capitalistas. Duarte (2019, p. 13) destaca que: "[...] o processo de transformação das consciências está, portanto, vinculado à transformação revolucionária da sociedade, ou seja, à superação da sociedade capitalista".

A atuação crítica do professor sobre as contradições da escola faz emergir espaços de luta dentro dela e na sociedade. Somente dessa forma que ocorrerá uma ruptura da lógica vigente em direção ao olhar para a realidade, possibilitando interferir sobre ela. Para Freres, Rabelo e Mendes Segundo (2008, p. 9):

Sob a lógica do capital, não há a menor possibilidade de realização de uma educação emancipadora, visto que ela, tendo esse sistema como base, necessariamente contribuirá para a disseminação dos interesses da classe dominante, bem como dos saberes que ela necessita para a produção. Somente numa sociedade emancipada - na qual o trabalho, matriz geradora da existência humana, estiver liberto dos grilhões do capital -, todo o sistema educacional será modificado para a reprodução social sem interesses de classes. 
A escola, por atender a necessidade do sistema capitalista, o qual reduz a participação dos estudantes da classe trabalhadora em níveis mais elevados da cadeia econômica, não permite a emancipação, pois caso isso fosse possível, eles sujeitos passariam a disputar os mesmos espaços da burguesia. Para ocorrer mudanças nos objetos da educação, é preciso mudança de consciência social.

A função da escola atual é reduzida, assim como são reduzidas as limitações e potencialidades no papel do professor, é possível destacar a crise e a necessidade de luta por uma escola que cumpra a sua função de transmissão do saber cientifico historicamente produzido e sistematizado e, por isso, se opor aos interesses da burguesia na sociedade capitalista, que não promove a emancipação humana por meio do conhecimento e condiciona o indivíduo a um conhecimento fragmentado e de senso-comum, subordinando-o à classe social determinada pelos detentores do poder, não viabilizando possibilidades de transformar as realidades impostas. É nesse sentido que se desenvolve a escola transformadora e humanizada. Para Saviani (2003, p.14): "[...] a escola diz respeito ao conhecimento elaborado e não ao conhecimento espontâneo; ao saber sistematizado e não ao saber fragmentado; a cultura erudita e não a cultura popular".

É importante lembrar que o conhecimento informal já ocorre permeado pela sociedade, e o que diferencia a escola é o acesso ao conhecimento científico. A família e os meios de comunicação social, por exemplo, fortalecem a manutenção do status quo, a primeira enquanto instituição reprodutora do que lhe é determinada pela sociedade capitalista, e os últimos, criando uma opinião pública que naturaliza os processos a partir da ideia hegemônica dessa mesma sociedade.

Faz-se necessário compreender que existe no capitalismo uma "[...] cisão entre a aparência e a essência, entre o direito e o fato, entre a forma e a matéria (ou o conteúdo)" (SAVIANI, 2017, p. 659). Essa discussão é ampliada, quando Saviani (2017, p. 659) afirma que o trabalhador "[...] se não vender sua força de trabalho ao capitalista, não terá como sobreviver, ele na verdade não tem escolha. Ou ele vende sua força de trabalho ou simplesmente vai morrer (sobra-lhe apenas a alternativa da delinquência, ou seja, enveredar pelo caminho do crime)". Para tanto, "[...] enquanto o capitalista é livre na aparência e na essência, de direito e de fato, formal e materialmente, o trabalhador é livre apenas na aparência, no plano do direito e no aspecto formal. Essencialmente, de fato e materialmente, ele é escravo". (SAVIANI, 2017, p. 659).

Enfim, na relação educação/escola/professor, o desafio se encontra para além da divisão econômica social política e suas determinações de classe, no reconhecimento pelo professor da essencialidade do seu papel enquanto agente transformador da realidade em sua totalidade, pois a partir dela é possível identificar as necessidades em busca de desenvolver estratégias para transformá-la, consciente de sua função: promover desenvolvimento e emancipação humana.

\section{À GUISA DE CONCLUSÃO - É POSSÍVEL LUTAR PELA ESCOLA?}

De acordo com a história da educação escolar e o papel do professor anteriormente descrita, a escola vem se tornando um espaço sem sentido e sem significado para a sociedade como um todo, ao ser desconsiderada enquanto potencial revolucionário na produção de conhecimento. Os indivíduos se veem cada vez mais distantes de seus objetivos na escolarização enquanto seres pensantes e passíveis de transformarem suas realidades.

O paradigma atual e a necessidade de uma escola pública transformadora no Brasil vêm se delineando nas últimas décadas a partir da universalização do ensino, permitindo o acesso à escola por todos. No entanto, esse acesso é relativo às condições particulares de cada instituição em cada contexto social, o que não é levado em consideração. Determina-se um padrão de escola e de ensino que limita a potencialidade do indivíduo, deixando-o na condição de sua capacidade imediatista, portanto nem o professor, nem o aluno, e nem a comunidade escolar tem sentido em seus papeis e na função da escola.

A universalização não é suficiente quando não se considera as condições particulares de cada contexto sócio-histórico. Mais especificamente, o professor, enquanto sujeito fundamental na mediação do conhecimento, vem atuando cada vez mais com menos autoridade quando, por exemplo, é considerado apenas como facilitador no pro- 
cesso de aprendizagem, desconsiderando seu papel ativo e criativo na relação dialética com o aluno. Nesta direção, é necessária uma reflexão conjunta e consciente sobre as necessidades do contexto para uma ação transformadora e humanizadora.

O professor se limita a um trabalho condicionado, sem objetividade, seduzido e orientado ao salário para a manutenção da sua sobrevivência material e social. Isso vai ao encontro da intencionalidade dos detentores do poder na sociedade de classes para a manutenção da divisão do trabalho, em que os indivíduos, ancorados por um discurso de "mercado", são aprisionados, com poucas condições para investirem em sua formação e assim, ampliar seus conhecimentos.

Apreender o contexto social e os fatores que o determinam, possibilita analisar cada unidade escolar, em sua organização didático pedagógica e de gestão, que implica em atuar sob condições particulares. De outra maneira, a educação promove o conhecimento da vida de forma consciente a fim de atender as necessidades do indivíduo; e a escola, enquanto instituição cientifica, possibilita o acesso ao conhecimento universal. O papel do professor, no contexto social de classes, necessita ir além de sua força motriz, pois terá que conhecer e enfrentar barreiras pedagógicas, econômicas, sociais, culturais e políticas, na luta pela sua função social no processo de emancipação dos indivíduos, com o objetivo de superar o conhecimento cotidiano que acaba sendo reproduzido na escola capitalista, e assim, promover o conhecimento científico sistematizado em cada realidade, para que esta possa ser transformada. Marx (1982, p. 25) afirma que "[...] não é a consciência dos homens que determina o seu ser, mas ao contrário, é o seu ser social que determina sua consciência". Desta forma, a solução dos problemas sociais do Brasil, como os da educação e da escola pública, fica condicionada à superação da ordem econômica que tem vigorado no país, especialmente para manter o status quo da classe privilegiada economicamente.

A partir das afirmações e constatações apresentadas neste texto, é possível afirmar que os objetivos propostos foram atingidos, especialmente quanto à reflexão sobre o papel do professor e da escola na sociedade capitalista. Foram breves discussões sobre as possibilidades e os desafios enfrentados, a fim de proporcionar aos alunos uma educação transformadora. Para tanto, foi realizado um exercício de reflexão sobre a necessidade de conscientizar e refletir sobre as possibilidades educativas do aluno e a busca incessante do professor na construção da sua identidade, assim como, constatar as condições limitantes que a escola atual propõe aos alunos, dificultando sua transformação e humanização.

\section{REFERÊNCIAS}

BRASIL. Base Nacional Comum Curricular/2017. Brasília: Ministério da Educação, 2017. Disponível em: http:// basenacionalcomum.mec.gov.br/images/BNCC_El_EF_110518_versaofinal_site.pdf. Acesso em: 11 dez. 2019

DUARTE, Newton. A catarse na didática da Pedagogia Histórico-Crítica. Revista Pro-Posições, Campinas-SP, v. 30, 2019.

FACCI, Marilda Gonçalves Dias. Valorização ou esvaziamento do trabalho do professor? um estudo crítico-comparativo da teoria do professor reflexivo, do construtivismo e da psicologia vigotskiana. Campinas-SP: Autores Associados, 2004.

FRERES, Helena de Araújo; RABELO, Jackline; MENDES SEGUNDO, Maria das Dores. O papel da educação na sociedade capitalista: uma análise onto-histórica. In.: V Congresso da Sociedade Brasileira de História da Educação, 2008.

KOSIK, Karel. Dialética do concreto. Rio de Janeiro: Paz e Terra, 1976.

MARX, Karl. Para a crítica da economia política. São Paulo: Abril Cultural, 1982. 
MÉSZÁROS, István. A educação para além do capital. São Paulo: Boitempo Editorial, 2005.

MARTINS, Cláudio Marques Nogueira; NOGUEIRA, Maria Alice. A sociologia da educação de Pierre Bourdieu: limites e contribuições. Revista Educação \& Sociedade, ano XXIII, n. 78, p. 15-36, abr. 2002. Disponível em: http:// www.scielo.br/pdf/es/v23n78/a03v2378. Acesso em: 11 dez. 2019.

PONCE, Aníbal. Educação e luta de classes. 14. ed. São Paulo: Cortez, 1995.

PUENTES, Roberto Valdéz; LONGAREZI, Andréa Maturano. Escola e didática desenvolvimental: seu campo conceitual na tradição da teoria histórico-cultural. Educ. rev. [online], v. 29, n.1, p. 247-271, 2013.

SAVIANI, Dermeval. A nova lei da educação: trajetória, limites e perspectivas. 2. ed. Campinas-SP: Autores Associados, 1997.

SAVIANI. Democracia, educação e emancipação humana: desafios do atual momento brasileiro. Psicologia Escolar e Educacional, São Paulo, v. 21, n. 3, set./dez. 2017.

SAVIANI, Dermeval. Educação Socialista, Pedagogia Histórico-Crítica e os desafios da sociedade de classes. In.: LOMBARDI, José Claudinei; SAVIANI, Dermeval (Org.). Marxismo e educação: debates contemporâneos. Campinas-SP: Autores Associados, 2002.

SAVIANI, Dermeval. Escola e democracia. 31. ed. Campinas-SP: Autores Associados, 1997.

SAVIANI, Dermeval. Pedagogia Histórico-Crítica: primeiras aproximações. 8. ed. Campinas-SP: Autores Associados, 2003. 